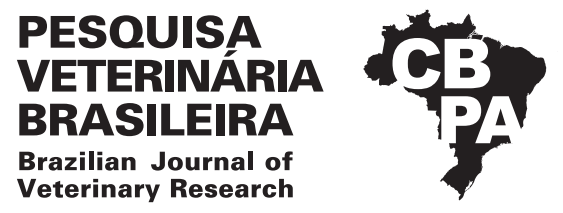

Pesq. Vet. Bras. 38(8):1570-1576, agosto 2018 DOI: 10.1590/1678-5150-PVB-5533

Artigo Original

Animais de Produção/Livestock Diseases

ISSN 0100-736X (Print)

ISSN 1678-5150 (Online)

\title{
Esteatose hepática altera acúmulo celular em tilápias do Nilo durante aerocistite infecciosa ${ }^{1}$
}

\author{
Alessandra C. Moraes ${ }^{2}$, Ed J.R. Prado², Elizabeth P. Foz ${ }^{3}$, Roberto Barbuioº ${ }^{2}$, \\ Vanessa P. Faria ${ }^{4}$ e Marco A.A. Belo ${ }^{2 *}$
}

\begin{abstract}
Moraes A.C., Prado E.J.R., Foz E.P., Barbuio R., Faria V.P. \& Belo M.A.A. 2018 [Hepatic steatosis alters cellular recruitment during induced aerocystitis in Nile tilapia.] Esteatose hepática altera acúmulo celular em tilápias do Nilo durante aerocistite infecciosa. Pesquisa Veterinária Brasileira 38(8):1570-1576. Faculdade de Ciências Agrárias e Veterinárias, Universidade Estadual Paulista "Júlio de Mesquita Filho", Via de Acesso Prof. Paulo Donato Castellane s/n, Jaboticabal, SP 14884-900, Brazil. E-mail: maabelo@hotmail.com

The study evaluated the hepatotoxicity induced by $\mathrm{CCl}_{4}$ during the glucocorticoid effect of dexamethasone (DEX) on the pathophysiology of the acute inflammatory reaction in Nile tilapia, Oreochromis niloticus, correlating hepatic functionality with cellular accumulation kinetics in infectious aerocystitis. Eighty- four Nile tilapia were distributed into four treatments: control, $\mathrm{CCl}_{4}, \mathrm{DEX}$ and $\mathrm{CCl}_{4}+\mathrm{DEX}$. Seven tilapia were sampled per treatment in three periods: 6,24 and $48 \mathrm{~h}$ after induction of inflammation. $\mathrm{CCl}_{4}$ was used in a single dose of $0.5 \mathrm{~mL} / \mathrm{kg}$ intraperitoneally to cause hepatic disorder. Aeromonas hydrophila inoculum was used to induce aerocystitis. Dexamethasone was administered intramuscularly at the dose of $2 \mathrm{mg} / \mathrm{kg} \mathrm{b}$. w. The results revealed a higher serum aspartate transaminase (AST) activity associated with greater somatic liver alteration, being these findings inversely proportional to the cellular accumulation in the inflammatory focus, demonstrating a lower number of inflammatory cells in the animals affected with a higher degree of hepatic disorders induced by $\mathrm{CCl}_{4}$. The histopathological study revealed transient degenerative changes in the most acute phase, as livers of tilapia showed accumulation of lipids in hepatocytes 6 hours after administration of $\mathrm{CCl}_{4}$, and this fatty degeneration was no longer observed in 24 and $48 \mathrm{~h}$. However, administration of $\mathrm{CCl}_{4}$ in Nile tilapia resulted in acute and transient liver degeneration, characterized by accumulation of fat in hepatocytes, increased AST in the blood and hepatomegaly. With liver dysfunction there was compromise of cellular recruitment in infectious aerocystitis, indicating that there is liver involvement in the innate immune response in tilapia.
\end{abstract}

INDEX TERMS: Hepatic steatosis, aerocystitis, tilapia, cichlid fish, carbon tetrachloride, acute inflammation, glucocorticoid.

RESUMO.- 0 presente estudo avaliou a hepatotoxicidade induzida pelo $\mathrm{CCl}_{4}$ durante o efeito glicocorticoide da dexametasona (DEX) na fisiopatologia da reação inflamatória aguda em

\footnotetext{
${ }^{1}$ Recebido em 13 de dezembro de 2017.

Aceito para publicação em 21 de dezembro de 2017.

${ }^{2}$ Faculdade de Ciências Agrárias e Veterinárias (FCAV), Universidade Estadual Paulista "Júlio de Mesquita Filho" (Unesp), Via de acesso Prof. Paulo Donato Castellane s/n, Jaboticabal, SP 14884-900, Brasil.

${ }^{3}$ Médica Veterinária Autônoma, Rua Daniel de Oliveira Carvalho 140, Cx. Postal 525, Porto Ferreira, SP 13660-971, Brasil.

${ }^{4}$ Laboratório de Patologia Clínica Max Vet Hospital Veterinário, Rua Tibúrcio de Souza 1490, São Paulo, SP 08140-000, Brasil. *Autor para correspondência: maabelo@hotmail.com
}

tilápias do Nilo, Oreochromis niloticus, correlacionando a funcionalidade hepática à cinética de acúmulo celular em aerocistite infecciosa. Para tal, utilizou-se 84 tilápias do Nilo distribuídas em 4 tratamentos: controle, $\mathrm{CCl}_{4}$, DEX e $\mathrm{CCl}_{4}+\mathrm{DEX}$. Sendo amostrados 7 animais por tratamento em três períodos, isto é: seis, 24 e $48 \mathrm{~h}$ após indução de inflamação. Utilizou-se $\mathrm{CCl}_{4}$ em dose única de $0,5 \mathrm{~mL} / \mathrm{kg}$, via intraperitoneal para causar o transtorno hepático. Para indução da aerocistite utilizou-se inóculo de Aeromonas hydrophila. A dexametasona foi administrada via intramuscular na dose de $2 \mathrm{mg} / \mathrm{kg}$ de peso vivo. Os resultados revelaram que quanto maior foi à atividade sérica de aspartato aminotransferase (AST) maior foi a alteração somática do fígado, sendo estes 
achados inversamente proporcionais ao acúmulo celular no foco inflamatório, demonstrando menor número de células inflamatórias nos animais acometidos com maior grau de distúrbios hepáticos induzidos pelo $\mathrm{CCl}_{4 .} \mathrm{O}$ estudo histopatológico revelou alterações degenerativas transitórias na fase mais aguda, pois os fígados das tilápias revelaram o acúmulo lipídeos nos hepatócitos $6 \mathrm{~h}$ após administração de $\mathrm{CCl}_{4}$, sendo esta degeneração gordurosa não mais observada nos tempos de 24 e 48h. Contudo, a administração de $\mathrm{CCl}_{4}$ em tilápias do Nilo resultou em degeneração hepática aguda e transitória, caracterizada pelo acúmulo de gordura nos hepatócitos, aumento de AST no sangue e hepatomegalia. Com a disfunção hepática houve comprometimento do recrutamento celular em aerocistite infecciosa, indicando que há participação do fígado na resposta imune inata em peixes.

TERMOS DE INDEXAČ̃̃O: Esteatose hepática, tilápias, aerocistite infecciosa, peixe ciclídeo, tetracloreto de carbono, esteatose, inflamação aguda, glicocorticoide.

\section{INTRODUÇÃO}

Diversos produtos químicos naturais e sintéticos provenientes das atividades domésticas, agrícolas e industriais são despejados sem tratamento prévio contaminando os ambientes aquáticos (Fernandes Neto \& Ferreira 2007). Além disso, complementa-se o uso indiscriminado de antiparasitários, antifúngicos, antibióticos para controle e prevenção de enfermidades em plantéis aquícolas. Estes compostos podem atuar como xenobióticos para os organismos aquáticos, compromentendo a saúde dos animais e a funcionalidade de órgãos como o fígado (Cabello 2006, Maradonna et al. 2015). Em sistemas de criação intensiva tem se observado o agravamento destas condições mórbidas, pois o arraçoamento com balanceamento nutricional inadequado pode causar desequilíbrio no metabolismo energético dos peixes, resultando em acúmulo de lipidios no citoplasma dos hepatócitos, evoluindo para alterações severas de degeneração gordurosa, também chamada de esteatose (Li et al. 2014, Zhang et al. 2014).

Estes comprometimentos na fisiologia hepática dos peixes, associados às condições de estresse em sistemas de criação intensiva, provocam depleção da imunocompetência dos animais, favorecendo o surto de enfermidades por agentes etiológicos oportunistas (Belo et al. 2005, 2014). 0 fígado exerce papel biológico importante no sistema imume, apresentando células de defesa residentes como linfócitos natural killers (NK) e células de Kupffer, além de participar da modulação da produção de proteinas reagentes da fase aguda (Gabay \& Kushner 1999), cujas concentrações sofrem significativas variações quando em contato com lipopolissacarideos bacterianos-LPS (Cray et al. 2010), assim mostrando-se como um importante sítio de regulação do sistema imune inato durante processos infecciosos e inflamatórios. No entanto, muitas destas funções não estão bem definidas em peixes teleósteos (Castro et al. 2014a, 2014b).

Modelos experimentais clássicos em mamíferos buscam avaliar a evolução fisiopatológica da esteatose, dentre estes se destaca o uso do tetracloreto de carbono, $\mathrm{CCl}_{4}$, que atua como agente hepatotóxico seletivo por induzir estresse oxidativo, resultado da liberação do radical triclorometil $\left(\mathrm{CCl}_{3}-\right)$, o qual é subsequentemente convertido em um radical peroxil na presença do oxigênio, iniciando a peroxidação de fosfolipídios da membrana citoplasmática, promovendo mudanças funcionais e morfológicas por acúmulos de produtos derivados deste processo oxidativo, causando severas injúrias nos tecidos hepáticos (Belo et al. 2009). Jia et al. (2014) determinaram o mecanismo de ação deste composto orgânico em Cyprinus carpio pela ativação da enzima citocromo P450 2E1 para formação de radicais livres altamente reativos no fígado da carpa, resultando em estresse oxidativo e peroxidação lipídica. De acordo com estes autores, o estresse oxidativo também desencadeou a liberação de fator de necrose tumoral alfa (TNF- $\alpha$ ) e o aumento do nível de receptor do tipo Toll 4 (TRL4), que por sua vez ativa factor nuclear kappa B

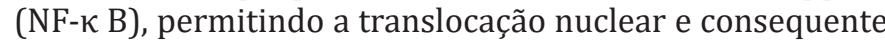
expressão de enzima óxido nítrico sintase induzível (iNOS) e interleucinas- $1 \beta$, -6 e 12 . Todos estes mecanismos levam ao comprometimento da função hepática com inflamação, esteatose, apoptose e necrose hepatocelular.

A dexametasona é um anti-inflamatório esteroidal, com ação imunossupressora uma vez que seu efeito resulta em linfopenia e leva a inibição da produção de várias citocinas, sendo cerca de vinte e cinco vezes mais potente que o cortisol (Parfitt et al. 1999), esteróide endógeno que em peixes teleósteos exerce efeitos glicocorticoides e mineralocorticóides (Belo et al. 2012a), participando da regulação do equilíbrio hidromineral, do metabolismo energético, além de suprimir o sistema imunológico e a capacidade reprodutiva dos animais (Bonga 1997).

Considerando a importância dos xenobióticos em ecossistemas aquáticos e o impacto destes compostos na saúde e bem estar dos peixes, o presente estudo avaliou a hepatotoxicidade induzida pelo $\mathrm{CCl}_{4}$ durante o efeito glicocorticóide da dexametasona na fisiopatologia da reação inflamatória aguda em tilápias do Nilo, Oreochromis niloticus, associado a funcionalidade hepática à cinética de acúmulo celular ao efeito em aerocistite infecciosa.

\section{MATERIAL E MÉTODOS}

Peixe e acondicionamento. Para a realização deste estudo foram utilizadas 84 tilápias do Nilo (Oreochromis niloticus), linhagem Gift, masculinizadas, com peso médio de $130 \mathrm{~g} \pm 25 \mathrm{~g}$, oriundos da mesma desova, acondicionadas em 12 tanques com 1000L de água cada em sistema de fluxo continuo. No período de aclimatação e durante o estudo manteve-se o fotoperíodo de 12 horas e o arraçoamento foi realizado duas vezes ao dia, 07:30 e 18:30h com ração Socil Laguna ${ }^{\circledR} 28 \%$.

Os parâmetros de qualidade da água foram examinados diariamente às 7:00 da manhã e às 6:00 da tarde (sonda portátil de pH com condutivímetro, modelo YSI-63 e oxímetro modelo YSI-55, Yellow Springs,Ohio/EUA) e apresentaram os seguintes intervalos de valores: temperatura $\left(25,6 \pm 1,8^{\circ} \mathrm{C}\right), \mathrm{pH}(6,6 \pm 0,4)$, oxigênio dissolvido $(5,3 \pm 0,5 \mathrm{mg} / \mathrm{L})$, condutividade elétrica $(89,8 \pm 12,3 \mathrm{mS} / \mathrm{cm})$.

Os protocolos de pesquisa e tratamento dos animais foram de acordo com os princípios e recomendações do Colégio Brasileiro de Experimentação Animal (COBEA) e aprovado pela Comissão de Ética no Uso de Animais (CEUA) da Universidade Estadual Paulista (Unesp), Campus de Jaboticabal/SP, com processo no 01040/13.

Anestesia. Para todas as manipulações, os peixes foram anestesiados por imersão em solução aquosa de benzocaína na proporção de 1:10.000 para tratamento e desafio e 1:500 para eutanásia (Manrique et al. 2015). 
Delineamento experimental. Os peixes foram distribuídos aleatoriamente em 12 caixas com capacidade de $1000 \mathrm{~L}$ de água cada, constituindo dois grupos: peixes que não receberam $\mathrm{CCl}_{4}$ e peixes que receberam $\mathrm{CCl}_{4}$. Estes grupos por sua vez receberam dois tipos de tratamentos: não tratados com dexametasona e tratados com dexametasona. Sendo amostrados sete animais por tratamento em três períodos, isto é: seis, 24 e 48 horas após indução da aerocistite infecciosa, para a avaliação da resposta no tempo, constituindo 12 grupos experimentais.

Indução da esteatose hepática. Para indução da esteatose hepática, utilizou-se $\mathrm{CCl}_{4}\left(\mathrm{Merck}^{\circledR}\right)$ em dose única de $0,5 \mathrm{~mL} / \mathrm{kg}$, homogeneizado com azeite de oliva na proporção de 1:1, v:v, administrado por via intraperitoneal adaptado de Belo et al. (2012b). No grupo sem tratamento com $\mathrm{CCl}_{4}$ houve à aplicação somente do azeite de oliva em mesmo volume e local para padronização do estímulo de manipulação.

Para visualização de acúmulo de lipídeos, fragmentos de fígado foram fixados em formol acrescido de cálcio, congelados em nitrogênio líquido e cortados em micrótomo criostático e assim submetidos a coloração de Sudan Black.

Indução do processo inflamatório. Para a indução do processo inflamatório utilizou-se inóculo da bactéria Aeromonas hydrophila na concentração de 6 X10 ${ }^{6}$ (Bozzo et al. 2007). 0 inóculo bacteriano foi identificado por sequenciamento genético (Sebastião et al. 2015). Neste sentido, foi injetado $1 \mathrm{~mL}$ do inóculo de Aeromonas hydrophila a $1 \mathrm{~cm}$ do final do opérculo, à altura da linha lateral, com auxílio de agulha e seringa estéril de $1 \mathrm{~mL}$, para atingir a bexiga natatória anterior no mesmo momento da indução da esteatose.

Administração de dexametasona. A administração da dexametasona (Cortvet ${ }^{\circledR}$ ) também foi realizada no momento da indução da esteatose nos grupos correspondentes, via intramuscular na região dorso-lateral esquerdo na concentração de $0,2 \%$ na dose de $2 \mathrm{mg} / \mathrm{kg}$ de peso vivo, segundo Viana (2007).
Os demais grupos foram submetidos à aplicação de solução fisiológica estéril em mesmo local e volume administração de dexametasona para padronização do estímulo de manipulação.

Avaliação do recrutamento celular na bexiga natatória. Para a avaliação do recrutamento de células totais na bexiga natatória, nos tempos pré-estabelecidos de 6, 24 e 48h foi injetado $1 \mathrm{~mL}$ de solução tampão fosfato salina, contendo ácido etilenodiaminotetracético (EDTA) a 0,09\%, à esquerda do final do opérculo, à altura da linha lateral, com auxílio de agulha e seringa estéril de $1 \mathrm{~mL}$ para atingir a bexiga natatória anterior seguindo protocolo descrito por Reque et al. (2010). Em seguida, realizou-se a necropsia com secção da bexiga natatória, e então recolhimento do volume total do exsudato com uma micropipeta. 0 volume recolhido foi centrifugado a $1000 \mathrm{rpm}$ por cinco minutos em centrífuga clínica. 0 sobrenadante foi desprezado, o sedimento total ressuspendido com a adição de volume conhecido de tampão fosfato. Uma alíquota desse volume foi transferida para câmara de Neubauer para contagem das células inflamatórias totais em microscopia de luz (Fig. 1). Realizado a contagem de 5 quadrantes correspondente a $0,02 \mu \mathrm{L}^{-1}$. Em seguida, multiplicou-se o valor de células encontrado na câmara de Neubauer pelo fator de diluição.

Bioquímica sérica. Foram colhidas amostras de sangue dos peixes por punção de vaso caudal sem anticoagulante e foram centrifugadas a 5.000rpm por cinco minutos para obtenção de soro em centrifuga de tubos (Modelo Quimis -Q222TM). Utilizou-se o soro para determinação da dosagem bioquímica de AST (aspartato aminotransferase), em analisador bioquímico semi-automático (Modelo LabQuest - BIOPLUS).

Avaliação de índice somático. Realizado a necropsia, com coleta do fígado para determinação do índice somático, através da proporção entre peso do órgão (PO) e peso corporal (PC). Calculado pela fórmula: Índice hepatossomático (IHS) = PO X 100/PC.

Metodologia estatística. Utilizou-se de forma conjunta a estatística multivariada e a univariada. Primeiramente utilizou-se

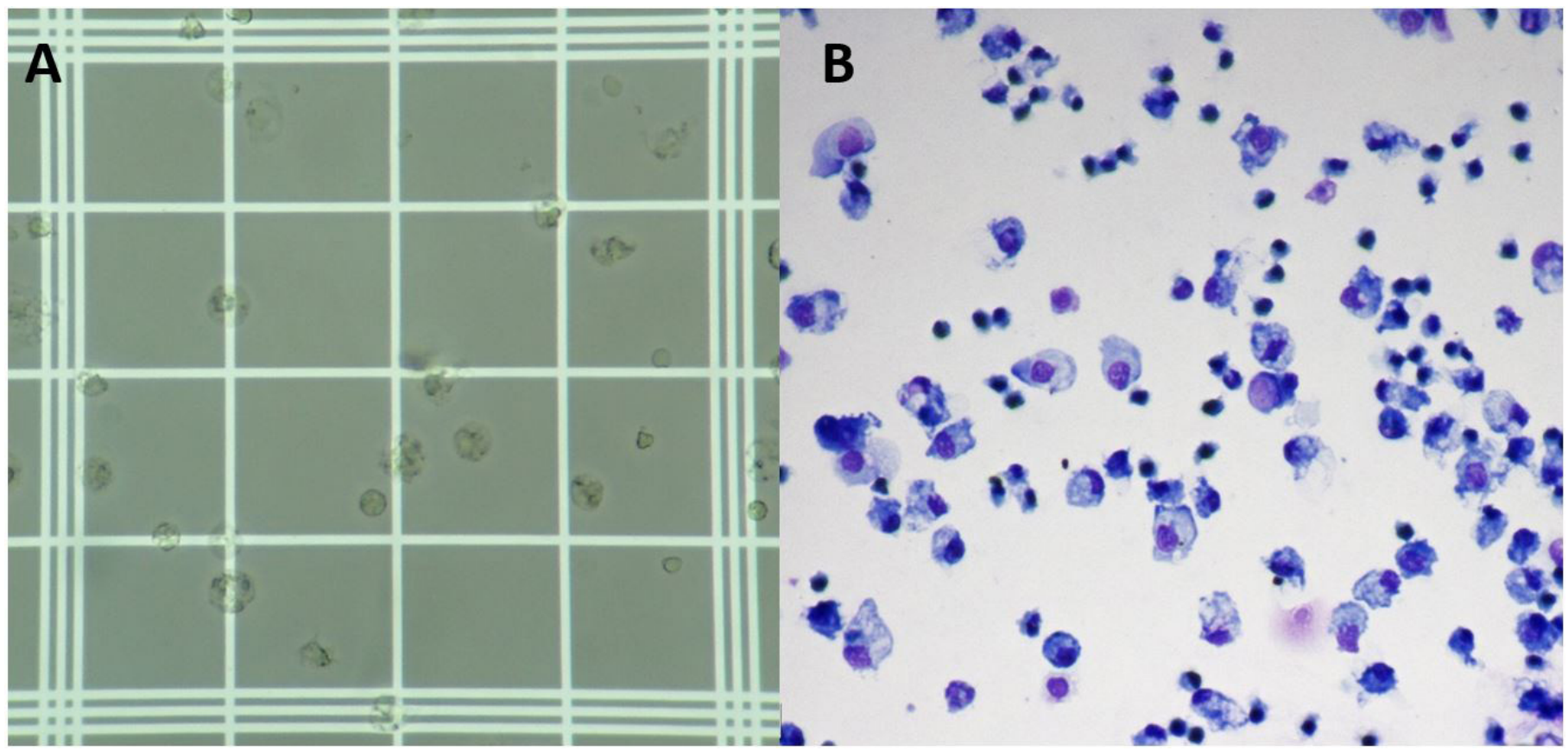

Fig.1. Fotomicrografia. (A) Visualização de alíquota de exsudato em câmara de Neubauer para contagem de células totais em microscopia de luz, obj.40x. (B) Extensão de alíquota de exsudato em lâmina de vidro com presença de células inflamatórias. Rosenfeld, obj.40x. 
a estatística multivariada por análise de fatores. Para tal, os dados foram padronizados e os autovalores foram extraídos segundo modelo de análise de componentes principais (Hair et al. 2009). Utilizou-se o critério de Kaiser (1958) para identificar novas variáveis latentes. Os valores das associações aceitas foram adotados de acordo com Streiner (2003). 0 escore fatorial resultante da análise multivariada foi submetido a análise univariada. Para a análise estatística univariada utilizou-se o modelo misto (Liu et al. 2010), aplicando o esquema experimental por parcelas subdivididas (Altman \& Krzywinski 2015) em um delineamento inteiramente casualizado: onde os peixes foram aleatorizado em grupo com aplicação de $\mathrm{CCl}_{4}$ e sem $\mathrm{CCl}_{4}$ (parcela principal), onde novamente foram aleatorizado para administração de dexametasona (parcela secundaria) e comparando as interações entre tratamento (unidades experimentais) ao longo do tempo 6, 24, 48h (Liu et al. 2010). Para estabelecer a hipótese estatística de homocedásticidade e normalidade dos resíduos padronizados internamente utilizou-se o teste BoxCox $(\lambda=1)$ e teste Shapiro-Wilk $(\mathrm{P}>0.05)$ respectivamente. Empregou-se o teste Tukey $(\mathrm{P}<0.05)$ para multicomparações entre as parcelas. Todas as análises estatísticas foram processadas no software SAS ${ }^{\circledR}$ (Statistical Analysis System), versão 9.3, (SAS 2012) Faculdade de Ciências Agrárias e Veterinárias (FCAV), UNESP/Jaboticabal, São Paulo.

\section{RESULTADOS E DISCUSSÃO}

Durante o estudo todos os parâmetros analisados de qualidade de água permaneceram dentro da faixa de conforto para tilápia (Sipaúba-Tavares 2013). Pela análise multivariada de componentes principais houve a extração de um processo, relacionando o recrutamento celular com propensão direcional oposta as variáveis IHS e AST, as quais apresentaram a mesma propensão de direção, ou seja, quanto maior foi à atividade sérica de AST maior foi a alteração somática do fígado, sendo estes achados inversamente proporcionais ao acúmulo celular no foco inflamatório, demonstrando menor número de células inflamatórias nos animais acometidos com maior grau de distúrbios hepáticos induzidos pelo $\mathrm{CCl}_{4}$ (Quadro 1).

A reação inflamatória decorre de vários mecanismos fisiopatológicos, entre estes se destaca a participação dos hepatócitos na regulação da produção proteínas da fase aguda (Gabay \& Kushner 1999), as quais apresentam diversas funções na modulação da resposta inflamatória de origem infecciosa ou não (Bayne \& Gerwick 2001), como neutralização de microrganismo, impedimento e sinalização de danos tecidual (Jensen et al. 1997). Portanto, havendo comprometimento do hepatócito haverá também alteração na sua funcionalidade e consequente alteração na regulação destas proteínas. Na reação inflamatória ocorre migração celular para o sítio inflamado por diapedese de células recrutadas do compartimento sanguíneo (Sakabe et al. 2013, Manrique et al. 2017, Petrillo et al. 2017), auxiliando o reestabelecimento e reparação tecidual, assim como, no combate de agentes infecciosos (Havixbeck et al. 2016, Bayona et al. 2017) e no controle da hemostasia exercido primordialmente por trombócitos (Ferdous \& Scott 2015).

A administração intraperitoneal de $\mathrm{CCl}_{4}$ resultou em alterações degenerativas transitórias na fase mais aguda (Fig.2), pois os fígados das tilápias revelaram o acúmulo lipídeos nos hepatócitos no tempo de 6 h após administração de $\mathrm{CCl}_{4}$, sendo esta degeneração gordurosa não mais observada nos tempos de 24 e 48h. Estes achados vão de encontro ao trabalho de Jia et al. (2014), os quais estudaram o efeito do $\mathrm{CCl}_{4}$ em Cyprinus carpio. Neste sentido, denomina-se o processo resultante da análise multivariada como regeneração hepática (Fig.3), pois ocorreu diminuição da atividade sérica de AST e do IHS das tilápias associado ao aumento do acúmulo celular no foco inflamado nos tempos de 24 e $48 \mathrm{~h}$, sugerindo a hipótese de recuperação da funcionalidade hepática. Tais achados corroboram estudos realizados com roedores após administração de $\mathrm{CCl}_{4}$ nos quais se observou mudanças hepáticas como hepatomegalia, esteatose, inflamação, infiltração celular, dilatação dos sinusóides e da veia centrolobular (Goessling \& Sadler 2015). Estas alterações hepáticas na fase mais aguda da intoxicação por este composto orgânico resultaram em aumento significativo do índice somático hepático em ratos Wistar (Belo et al. 2012b). De acordo com Lawrence \& Steiner (2017), o aumento da atividade de AST no soro é considerado um marcador sensível para a lesão hepatocelular principalmente quando associado a outros indicadores de lesões hepáticas como a esteatose.

No tempo de $6 \mathrm{~h}$ ficou evidente o efeito glicocorticoide da dexametasona sobre as alterações hepáticas, pois peixes que receberam $\mathrm{CCl}_{4}$ e foram tratados com dexametasona não apresentaram o mesmo grau de comprometimento no tecido hepático apresentado por peixes somente intoxicados com $\mathrm{CCl}_{4}$ (Fig.3). Uma hipótese que justifica estes achados refere-se ao efeito glicocorticoide diminuir a infiltração de células inflamatórias no tecido hepático lesado por $\mathrm{CCl}_{4}$ fato que amenizou os efeitos deletérios determinados por este composto orgânico. A intoxicação aguda com $\mathrm{CCl}_{4}$ em roedores revelou aumento de infiltração celular no tecido hepático à ocorrência de esteatose e necrose no tecido hepático (Belo et al. 2012b). Claudiano et al. (2013) demonstraram o efeito glicocorticoide da dexametosona sobre a diminuição significativa de acúmulo celular em foco inflamatório de pacus. Por outro lado, a dexametosa também está relacionada à doença hepática não alcoólica (Woods et al. 2015), promovendo o aumento da biossíntese lipídica no fígado que pode levar a esteatose hepática com seu uso crônico (Mahendran \& Devi 2001, D’Souza et al. 2012). No entanto, neste estudo tanto o $\mathrm{CCl}_{4}$ quanto a dexametasona foram administrados uma única vez e o comprometimento hepático manifestou-se de forma transitória, justificando tais achados. A ação do $\mathrm{CCl}_{4}$ provoca dano tecidual e consequente resposta inflamatória no fígado com a liberação de mediadores pró-Inflamatórios. Em estudo realizado por Cao et al. (2015), observou-se que IHS apresentou-se extremamente aumentado em carpas (Cyprinus carpio var. Jian) que receberam $\mathrm{CCl}_{4}$ em relação as carpas do grupo controle. No entanto, o uso de curcumina não se

Quadro 1. Associação entre as variáveis AST, IHS e recrutamento celular na aerocistite aguda em tilápias do Nilo (n=84) submetidas à administração de $\mathrm{CCl}_{4}$

\begin{tabular}{lc}
\hline \multicolumn{1}{c}{ Variáveis } & Regeneração hepáticac $^{\mathrm{c}}$ \\
\hline Aspartato aminotransferase (AST) & $-0,70$ \\
Índice hepatossomático (IHS) & $-0,75$ \\
Recrutamento celular na bexiga natatória $^{\text {Autovalores }}{ }^{\mathrm{b}}$ & 0,74 \\
$\%$ de variância & 1,60
\end{tabular}

a Resultados extraídos pelo método de componentes principais para a análise de fatores no estudo de padrões na multivariada, ${ }^{\mathrm{b}}$ autovalores $\geq 1$ de acordo com Kaiser (1958), ' marcação $\geq 70$ segundo Streiner (2003). 


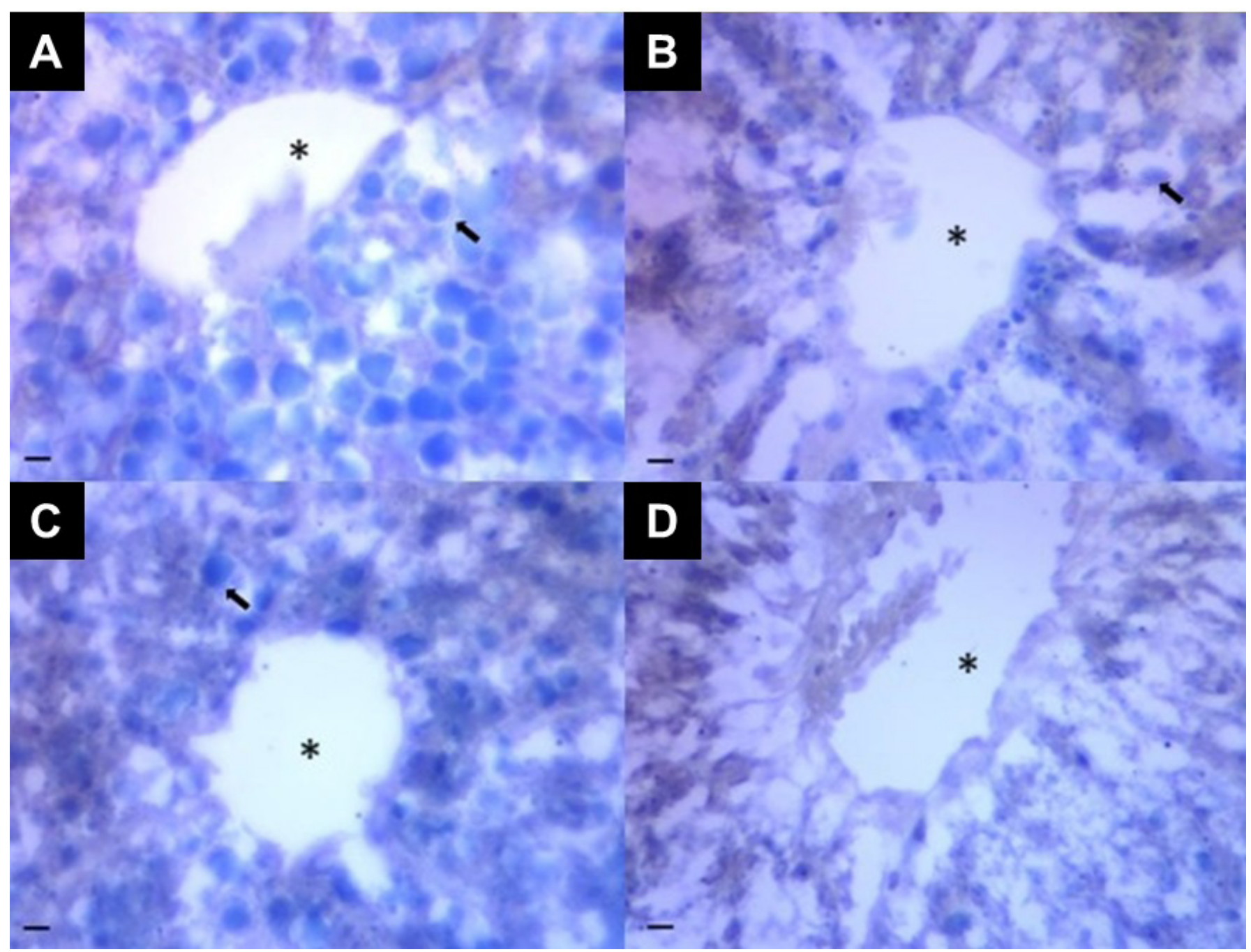

Fig.2. Fígado de tilápias do Nilo após administração do $\mathrm{CCl}_{4}$ : (A) 6 horas após a administração, (B) 24 horas após a administração, (C) 48 horas após a administração, (D) controle. Hepatócitos com acumulo de lipídeos (seta), veia central (asterisco). Sudan Black, obj.40x. Barra $=100 \mu \mathrm{m}$.

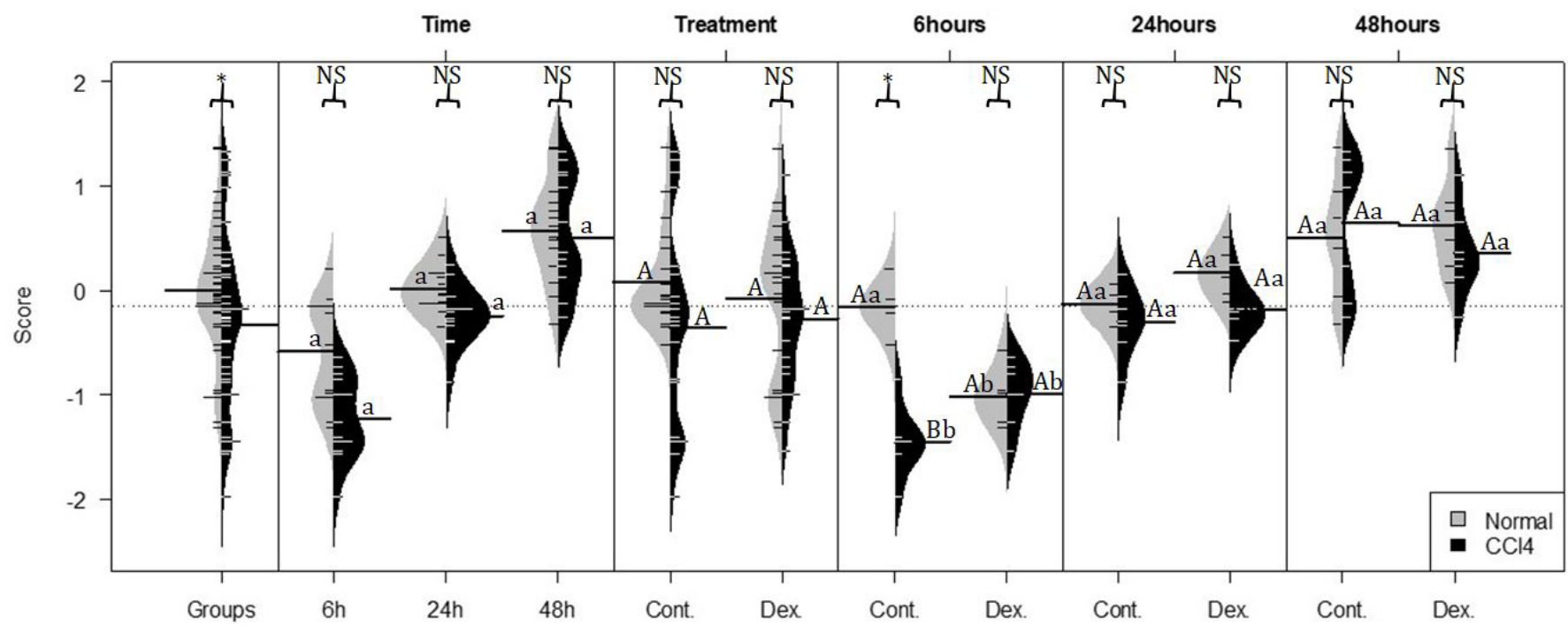

Fig.3. Processo de regeneração hepática formada por análise de fatores entre tilápias com aerocistite, submetidas a administração de $\mathrm{CCl}_{4}$ e tratadas com dexametasona. Colchete $\left(\Gamma^{\perp} 7\right.$ ) compara a diferença entre o grupo que recebeu $\mathrm{CCl}_{4}$ e o que não recebeu CCl${ }_{4}$, letras minúsculas comparam cada grupo ao longo do tempo, letra maiúscula compara a diferença entre os tratamentos. Teste de comparação Tukey com nível de significância $P=<0,05$ * Significativo, NS=não significativo. 
observou este efeito decorrente de seu efeito anti-inflamatório. Também se observou em estudo in vitro com hepatócitos de carpa que um polissacarídeo do cogumelo Ganoderma lucidum apresentou efeito anti-inflamatório por inibição de TNF-a e IL-1 $\beta$ e também por citocinas imunorreguladoras (Liu et al 2015). Neste sentido estes dados corroboram a hipótese de que o efeito anti-inflamatório da dexametosona tenha contribuído para amenizar as alterações hepáticas decorrentes da exposição ao $\mathrm{CCL}_{4}$.

\section{CONCLUSÕES}

A intoxicação por $\mathrm{CCl}_{4}$ em tilápias do Nilo resultou em degeneração hepática aguda e transitória, caracterizada pelo acúmulo de gordura nos hepatócitos, aumento da atividade de AST no sangue e hepatomegalia.

Com a disfunção hepática houve comprometimento do recrutamento celular em aerocistite infecciosa, indicando que há participação do fígado na resposta imune inata das tilápias. Por outro lado, o glicocorticoide dexametasona amenizou o efeito lesivo do $\mathrm{CCl}_{4}$ no fígado devido sua ação anti-inflamatória.

Contudo, os resultados desta investigação demonstraram a eficácia do modelo experimental clássico com $\mathrm{CCl}_{4}$ para estudos de hepatotoxicidade em tilápias do Nilo, assim como, a sua viabilidade para estudos com hepatoprotetores que auxiliem a funcionalidade do fígado, permitindo avaliar a participação hepática na modulação de respostas de defesa.

Agradecimentos.- Ao Conselho Nacional de Desenvolvimento Científico e Tecnológico (CNPq) e à Fundação de Amparo à Pesquisa do Estado de São Paulo, (FAPESP, 10/09300-9).

\section{REFERÊNCIAS}

Altman N. \& Krzywinski M. 2015. Points of significance: split plot design. Nat. Methods 12(3):165-166. <http://dx.doi.org/10.1038/nmeth.3293> <PMid:25879095>

Bayne C.J. \& Gerwick L. 2001. The acute phase response and innate immunity of fish. Dev. Comp. Immunol. 25(8/9):725-743.<http://dx.doi.org/10.1016/ S0145-305X(01)00033-7><PMid:11602193>

Bayona J.A.M., Karuppannan A.K., Trites M.J. \& Barreda D.R. 2017. Application of imaging flow cytometry for characterization of acute inflammation in non-classical animal model systems. Methods 112:167-174. <http://dx.doi. org/10.1016/j.ymeth.2016.06.013><PMid:27327146>

Belo M.A.A., Schalch S.H.C., Moraes F.R., Soares V.E., Otoboni A.M.M.B. \& Moraes J.E.R. 2005. Effect of dietary supplementation with vitamin $\mathrm{E}$ and stocking density on macrophage recruitment and giant cell formation in the teleost fish, Piaractus mesopotamicus. J. Comp. Pathol. 133(2/3):146154.<http://dx.doi.org/10.1016/j.jcpa.2005.04.004><PMid:16033696>

Belo M.A.A., Souza L.M., Soares V.E., Sobreira M.F.R., Cassol D.M.S. \& Toma S.B. 2009. Tratamento hepatoprotetor favorece a resposta leucocitária de ratos wistar intoxicados por CCl4. Arch. Vet. Sci. 14(2):74-82. <http:// dx.doi.org/10.5380/avs.v14i2.12633>

Belo M.A.A., Moraes J.R.E., Soares V.E., Martins M.L., Brum C.D. \& Moraes F.R. 2012a. Vitamin $C$ and endogenous cortisol in foreign-body inflammatory response in pacus. Pesq. Agropec. Bras. 47(7):1015-1021.<http://dx.doi. org/10.1590/S0100-204X2012000700019>

Belo M.A.A., Soares V.E., Souza L.M., Sobreira M.F.R., Cassol D.M.S. \& Toma S.B. 2012b. Hepatoprotective treatment attenuates oxidative damages induced by carbon tetrachloride in rats. Exp. Toxicol. Pathol. 64(3):155165. <http://dx.doi.org/10.1016/j.etp.2010.08.001> <PMid:20832266>
Belo M.A.A., Moraes F.R., Yoshida L., Prado E.J.R., Moraes J.R.E., Soares V.E \& Silva M.G. 2014. Deleterious effects of low level of vitamin E and high stocking density on the hematology response of pacus, during chronic inflammatory reaction. Aquaculture 422:124-128. <http://dx.doi. org/10.1016/j.aquaculture.2013.12.013>

Bonga S.E.W. 1997. The stress response in fish. Physiol. Rev. 77(3):591-625. <http://dx.doi.org/10.1152/physrev.1997.77.3.591><PMid:9234959>

Bozzo F.R., Moraes J.R.E., Moraes F.R., Pereira G.T., Tavares-Dias M. \& Onaka E.M. 2007. Kinetics of cellular component in inflammatory response induced by different stimuli in the swim bladder of Piaractus mesopotamicus Holmberg 1887 (Characidae). J. World Aquacult. Soc. 38(2):302-308. <http://dx.doi. org/10.1111/j.1749-7345.2007.00100.x>

Cabello F.C. 2006. Heavy use of prophylactic antibiotics in aquaculture: a growing problem for human and animal health and for the environment. Environ. Microbiol.8(7):1137-1144.<http://dx.doi.org/10.1111/j.1462-2920.2006.01054. x> <PMid:16817922>

Cao L., Ding W., Du J., Jia R., Liu Y., Zhao C., Shen Y. \& Yin G. 2015. Effects of curcumin on antioxidative activities and cytokine production in Jian carp (Cyprinus carpio var. Jian) with CCl4-induced liver damage. Fish Shellfish Immunol. 43(1):150-157. <http://dx.doi.org/10.1016/j.fsi.2014.12.025> $<$ PMid:25549934>

Castro M.P., Moraes F.R., Fujimoto R.Y., Cruz C., Belo M.A.A. \& Moraes J.R.E. 2014a. Acute toxicity by water containing hexavalent or trivalent chromium in native Brazilian fish, Piaractus mesopotamicus: anatomopathological alterations and mortality. Bull. Environ. Contam. Toxicol. 92(2):213-219. <http://dx.doi.org/10.1007/s00128-013-1174-5> <PMid:24346495>

Castro M.P., Claudiano G.S., Petrillo T.R., Shimada M.T., Belo M.A., MarzocchiMachado C.M., Moraes J.R., Manrique G.W. \& Moraes F.R. 2014b. Acute aerocystitis in Nile tilapia bred in net cages and supplemented with chromium carbochelate and Saccharomyces cerevisiae. Fish Shellfish Immunol. 36(1):284-290. <http://dx.doi.org/10.1016/j.fsi.2013.11.012> <PMid:24309138>

Claudiano G.S., Petrillo T.R., Manrique W.G., Castro M.P., Loureiro B.A., Marcusso P.F., Belo M.A.A., Moraes J.R.E. \& Moraes F.R. 2013. Acute aerocystitis in Piaractus mesopotamicus: participation of eicosanoids and pro-inflammatory cytockines. Fish Shellfish Immunol. 34(5):1057-1062. <http://dx.doi. org/10.1016/j.fsi.2013.01.006><PMid:23370015>

Cray C., Besselsen D.G., Hart J.H., Yoon D., Rodriguez M., Zaias J.N.A. \& Altman N.H. 2010. Quantitation of Acute Phase Proteins and Protein Electrophoresis in Monitoring the Acute Inflammatory Process in Experimentally and Naturally Infected Mice. Comp. Med. 60(4):263-271. <PMid:20819375>

D’Souza A.M., Beaudry J.L., Szigiato A.A., Trumble S.J., Snook L.A., Bonen A., Giacca A. \& Riddell M.C. 2012. Consumption of a high-fat diet rapidly exacerbates the development of fatty liver disease that occurs with chronically elevated glucocorticoids. Am. J. Physiol. Gastrointest. Liver Physiol.302(8):G850-G863.<http://dx.doi.org/10.1152/ajpgi.00378.2011> $<$ PMid:22268100>

Ferdous F. \& Scott T.R.A. 2015. Comparative examination of thrombocyte/ platelet immunity. Immunol. Lett. 163(1):32-39. <http://dx.doi.org/10.1016/j. imlet.2014.11.010><PMid:25448707>

Fernandes Neto M.L.F. \& Ferreira A.P. 2007. Perspectivas da sustentabilidade ambiental diante da contaminação química da água: desafios normativos. Interfacehs 2(4):1-15.

Gabay C. \& Kushner I. 1999. Acute-phase proteins and other systemic responses to inflammation. N. Engl. J. Med. 340(6):448-454. <http://dx.doi. org/10.1056/NEJM199902113400607><PMid:9971870>

Goessling W. \& Sadler K.C. 2015. Zebrafish: an important tool for liver disease. Gastroenterology 149(6):1361-1377. <http://dx.doi.org/10.1053/j. gastro.2015.08.034 ><PMid:26319012>

Hair J.F., Black W.C., Barry J.B. \& Anderson R.E. 2009. Multivariate Data Analysis. 7th ed. Upper Saddle River Prentice Hall. 785p. 
Havixbeck J.J., Rieger A.M., Wong M.E., Hodgkinson J.W. \& Barreda D.R. 2016. Neutrophil contributions to the induction and regulation of the acute inflammatory response in teleost fish. J. Leukoc. Biol. 99(2):241252. <http://dx.doi.org/10.1189/jlb.3HI0215-064R><PMid:26292979>

Jensen L.E., Hiney M.P., Shields D.C., Uhlar C.M., Lindsay A.J. \& Whitehead A.S. 1997. Acute phase proteins in salmonids: evolutionary analyses and acute phase response. J. Immunol. 158(1):384-392. <PMid:8977214>

Jia R., Cao L.P., Du J.L., Wang J.H., Liu Y.J., Jeney G., Xu P. \& Yin G.J. 2014. Effects of carbon tetrachloride on oxidative stress, inflammatory response and hepatocyte apoptosis in common carp (Cyprinus carpio). Aquat. Toxicol. 152:11-19. <http://dx.doi.org/10.1016/j.aquatox.2014.02.014> $<$ PMid:24721155>

Kaiser H.F. 1958. The varimax criterion for analytic rotation in factor analysis. Psychometrika 23(3):187-200.

Lawrence Y.A. \& Steiner J.M. 2017. Laboratory Evaluation of the Liver. J. Small. Anim. Pract. 47(3):539-553.

Li J.Y., Zhang D.D., Xu W.N., Jiang G.Z., Zhang C.N., Li X.F. \& Liu W.B. 2014. Effects of dietary choline supplementation on growth performance and hepatic lipid transport in blunt snout bream (Megalobrama amblycephala) fed high-fat diets. Aquaculture 434:340-347. <http://dx.doi.org/10.1016/j. aquaculture.2014.08.006>

Liu C., Cripe T.P. \& Kim M.O. 2010. Statistical issues in longitudinal data analysis for treatment efficacy studies in the biomedical sciences. Mol. Ther. 18(9):1724-1730. <http://dx.doi.org/10.1038/mt.2010.127> $<$ PMid:20588256>

Liu Y.J., Du J.L., Cao L.P., Jia R., Shen Y.J., Zhao C.Y., Xu P. \& Yin G.J. 2015. Anti-inflammatory and hepatoprotective effects of Ganoderma lucidum polysaccharides on carbon tetrachloride-induced hepatocyte damage in common carp (Cyprinus carpio L.). Int. Immunopharmacol. 25(1):112-120. <http://dx.doi.org/10.1016/j.intimp.2015.01.023> <PMid:25639226>

Mahendran P. \& Devi C.S. 2001. Effect of Garcinia cambogia extract on lipids and lipoprotein composition in dexamethasone administered rats. Indian J. Physiol. Pharmacol. 45(3):345-350.<PMid:11881574>

Manrique M.G., Figueiredo M.A.P., Belo M.A.A., Martins M.L. \& Moraes F.R. 2017. Chronic granulomatous inflammation in teleost fish Piaractus mesopotamicus: histopathology model study. Revta MVZ Cordoba 22(1):57385746. <http://dx.doi.org/10.21897/rmvz.933>

Manrique W.G., Claudiano G.S., Castro M.P., Petrillo T.R., Figueiredo M.A.P., Belo M.A.A., Berdeal M.I.Q., Moraes J.R.E. \& Moraes F.R. 2015. Expression of cellular components in granulomatous inflammatory response in Piaractus mesopotamicus model. Plos One 10(3):e0121625. <http://dx.doi. org/10.1371/journal.pone.0121625><PMid:25811875>
Maradonna F., Nozzi V., Santangeli S., Traversi I., Gallo P., Fattore E., Mita D.G., Mandich A. \& Carnevali O. 2015. Xenobiotic-contaminated diets affect hepatic lipid metabolism: Implications for liver steatosis in Sparus aurata juveniles. Aquat. Toxicol. 167:257-264. <http://dx.doi.org/10.1016/j. aquatox.2015.08.006><PMid:26382854>

Parfitt K., Sweetman S.C., Blake P.S. \& Parsons A.V. 1999. Corticosteroids, p.1010-1051. In: Parfitt K. \& Martidale W. (Ed.), The Complete Drug Reference. 32nd ed. Pharnmaceutical Press, London.

Petrillo T.R., Claudiano G.S., Yunis-Aguinaga J., Manrique W.G., Castro M.P., Belo M.A.A., Moraes J.R.E. \& Moraes F.R. 2017. Influence of dexamethasone and levamisole on macrophage recruitment, giant cell formation and blood parameters in the tropical fish Piaractus mesopotamicus. Biosci. J. 33:1015-1027. <http://dx.doi.org/10.14393/BJ-v33n4a2017-33016>

Reque V.R., Moraes J.E.R., Belo M.A.A. \& Moraes F.R. 2010. Inflammation induced by inactivated Aeromonas hydrophila in Nile tilapias fed diets supplemented with Saccharomyces cerevisiae. Aquaculture 300(1):37-42. <http://dx.doi.org/10.1016/j.aquaculture.2009.12.014>

Sakabe R., Moraes F.R., Belo M.A.A., Pilarski F. \& Moraes J.R.E. 2013. Kinetics of chronic inflammation in Nile tilapia fed n-3 and n-6 essential fatty acids. Pesq. Agropec. Bras. 48(3):313-319. <http://dx.doi.org/10.1590/S0100204X2013000300010>

SAS 2012. The SAS-System for Windows. User's Guide. Versão 9.3. Statistical Analysis System Institute, Cary.

Sebastião F.A., Furlan L.R., Hashimoto D.T. \& Pilarski F. 2015. Identification of bacterial fish pathogens in Brazil by direct colony PCR and 16S rRNA Gene Sequencing. Adv. Microbiol. 5(06):409-424. <http://dx.doi.org/10.4236/ aim.2015.56042>

Sipaúba-Tavares L.H. 2013. Uso Racional da Água em Aquicultura. Funep.189p.

Streiner D.L. 2003. Starting at the beginning: an introduction to coefficient alpha and internal consistency. J. Pers. Assess. 80(1):99-103. <http://dx.doi. org/10.1207/S15327752JPA8001_18> <PMid:12584072>

Viana F.A.B. 2007. Guia Terapêutico Veterinário. 2aㅡ ed. Cem, Lagoa Santa, MG. 462p.

Woods C.P., Hazlehurst J.M. \& Tomlinson J.W. 2015. Glucocorticoids and non-alcoholic fatty liver disease. J. Steroid Biochem. Mol. Biol. 154:94-103. <http://dx.doi.org/10.1016/j.jsbmb.2015.07.020> <PMid:26241028>

Zhang D., Lu K., Dong Z., Jiang G., Xu W. \& Liu W. 2014. The effect of exposure to a high-fat diet on microRNA expression in the liver of blunt snout bream (Megalobrama amblycephala). PLos One 9(5):e96132. <http://dx.doi. org/10.1371/journal.pone.0096132><PMid:24788396> 